\title{
Correction to: Appendicolith appendicitis is clinically complicated acute appendicitis-is it histopathologically different from uncomplicated acute appendicitis
}

\author{
Jari Mällinen ${ }^{1,2}$ (D) S Siina Vaarala ${ }^{3,4}$ - Markus Mäkinen ${ }^{3,4} \cdot$ Elina Lietzén $^{5,6} \cdot$ Juha Grönroos ${ }^{5,6}$ Pasi Ohtonen $^{2}$ • \\ Tero Rautio $^{1,2}$ - Paulina Salminen ${ }^{5,6,7}$
}

Published online: 3 March 2020

(C) Springer-Verlag GmbH Germany, part of Springer Nature 2020

\section{Correction to: International Journal of Colorectal Disease (2019) 34:1393-1400 \\ https://doi.org/10.1007/s00384-019-03332-Z}

The authors regrets that a typo error found on their published paper. The corrections are as follows:

As mentioned in Materials and Methods (p. 1395), the inflammatory cell count was performed on predefined 0.100 $\mathrm{mm}^{2}$ areas. In Tables 2 and 3 of the published article, the predefined areas are falsely claimed to be $1 \mathrm{~mm}^{2}$. The Tables 2 and 3 shows the corrected numbers.

Same corrections concerning these areas should also be made in the Abstract (p. 1393). The Results section of the Abstract should be as follows (corrections in bold): Using multivariate logistic regression models adjusted for age, gender, and symptom duration, statistically significant differencies were detected in the depth of inflammation $\leq 2.8 \mathrm{~mm}$ (adjusted OR 2.18 (95\% CI: 1.29-3.71, $\mathrm{p}=0.004)$, microabscesses(adjusted OR 2.16 (95\% CI:

The online version of the original article can be found at https://doi.org/10. 1007/s00384-019-03332-z

Jari Mällinen

jari.mallinen@gmail.com

Department of Surgery, Oulu University Hospital, Oulu, Finland

2 Division of Operative Care, Oulu University Hospital and Medical Research Center Oulu, University of Oulu, Oulu, Finland

3 Cancer and Translational Medicine Research Unit, University of Oulu and Department of Pathology, Oulu University Hospital,

Oulu, Finland
$1.22-3.83, \mathrm{p}=0.008)$, the number of eosinophils and neutrophils $\geq 150 / \mathbf{0 . 1} \mathbf{~ m m}^{2}$ (adjusted OR 0.97 (95\% CI: 0.95-0.99, $\mathrm{p}=0.013$ ), adjusted OR 3.04 (95\%CI: 1.82 $5.09, \mathrm{p}<0.001$, respectively).

Same corrections concerning these areas should also be made in the Results section of the article (p. 1396) (corrections in bold): The neutrophilic granulocyte infiltration was more frequently dense in appendicolith appendicitis $(42.7 \%$ vs $\left.19.6 \% \geq 150 / \mathbf{0 . 1} \mathbf{~ m m}^{2}, \mathrm{p}<0.001\right)$, whereas the number of eosinophils was higher in uncomplicated acute appendicitis (11.0/ $\mathbf{0 . 1} \mathbf{~ m m}^{2}$ vs $\left.6.9 / \mathbf{0 . 1} \mathbf{~ m m}^{2}, \mathrm{p}=0.001\right)$. The value of 150 neutrophils $/ \mathbf{0 . 1} \mathbf{~ m m}^{2}$ gave $80 \%$ specificity and therefore was used as a cut-off point.

The original article remain unchanged.
4 Medical Research Center Oulu, Oulu, Finland

5 Division of Digestive Surgery and Urology, Turku University Hospital, Turku, Finland

6 Department of Surgery, University of Turku, Turku, Finland

7 Satakunta Central Hospital, Pori, Finland 
Table 2 The histopathologic parameters measured

\begin{tabular}{llll}
\hline & $\begin{array}{l}\text { Uncomplicated acute } \\
\text { appendicitis, } n=187\end{array}$ & $\begin{array}{l}\text { Appendicolith } \\
\text { appendicitis, } n=157\end{array}$ & $p$ value \\
\hline Max diameter of appendix, mm, mean & $7.954(1682)$ & $9.181(2107)$ & $<0.001$ \\
$\quad(\mathrm{SD}) . n / N(\%)$ & $138 / 187(73.8)$ & $141 / 157(89.8)$ & .007 \\
Depth of inflammation, mm, mean & $3.641(1038)$ & $3.325(1001)$ & \\
$\quad(\mathrm{SD}), n / N(\%)$ & $165 / 187(88.2)$ & $145 / 157(92.4)$ & .003 \\
$\leq 2.8 \mathrm{~mm}, n / N(\%)$ & $33 / 165(20.0)$ & $51 / 145(35.2)$ & $<0.001$ \\
Superficial mucosal damage, $n / N(\%)$ & $44 / 187(23.5)$ & $75 / 157(47.7)$ & $<0.001$ \\
Deep mucosal damage, $n / N(\%)$ & $27 / 187(14,4)$ & $77 / 157(49.0)$ & $<0.001$ \\
Neutrophils, $\mathrm{n} / 0.1 \mathrm{~mm}^{2}$ & & & \\
$\quad<150, n / N(\%)$ & $144 / 179(80.4)$ & $62 / 143(57.3)$ & .001 \\
$\quad \geq 150, n / N(\%)$ & $35 / 179(19.6)$ & $6.143(42.7)$ & .016 \\
Eosinophils, $\mathrm{n} / 0.1 \mathrm{~mm}^{2}$, mean $(\mathrm{SD})$ & $11.0(14.5)$ & & \\
Micro-abscesses & & $119 / 156(76.3)$ & \\
No abscesses & $162 / 187(86.6)$ & $37 / 156(23.7)$ & \\
One or multiple abscesses & $25 / 187(13.4)$ & & \\
Presence of fecal material & & $63 / 156(40.4)$ & \\
No fecal material $n / N(\%)$ & $155 / 187(82.9)$ & $67 / 156(42.9)$ & \\
Appendicolith $n / N(\%)$ & $9 / 187(4.8)$ & & \\
Fecal material & $23 / 187(12.3)$ & & \\
\hline
\end{tabular}

Table 3 The results of logistic regression analysis for the presence of acute appendicitis with appendicolith. The results are presented as odds ratio (OR) with $95 \%$ confidence interval (95\% CI)

\begin{tabular}{llllr}
\hline Variable & Univariate OR & Adjusted ${ }^{1}$ OR & 95\% CI & $p$ value \\
\hline Microabscess & 2.02 & 2.16 & 1.22 to 3.83 & 0.008 \\
Eosinophils, $n / 0.1 \mathrm{~mm}^{2}$ & 0.97 & 0.97 & 0.95 to 0.99 & 0.013 \\
Neutrophils, $\geq 150 / 0.1 \mathrm{~mm}^{2}$ & 3.06 & 3.04 & 1.82 to 5.09 & $<0.001$ \\
Faecal material & 5.37 & 6.05 & 3.45 to 10.59 & $<0.001$ \\
Depth of inflammation, $\leq 2800 \mu \mathrm{m}$ & 2.17 & 2.18 & 1.29 to 3.71 & 0.004 \\
\hline
\end{tabular}

${ }^{1}$ Adjusting variables age, sex and duration of symptoms. 